Article

\title{
Anti-Amyloidogenic Properties of Some Phenolic Compounds
}

\author{
Afsaneh Porzoor ${ }^{1}$, Benjamin Alford ${ }^{2}$, Helmut M. Hügel ${ }^{\text {, }}$ Danilla Grando ${ }^{1}$, Joanne Caine ${ }^{3}$,
} and Ian Macreadie ${ }^{1, *}$

1 School of Applied Sciences, RMIT University, Bundoora, Victoria 3083, Australia;

E-Mails: afsaneh.porzoor@rmit.edu.au (A.P.); danilla.grando@rmit.edu.au (D.G.)

2 School of Applied Sciences, RMIT University, Melbourne, Victoria 3000, Australia; E-Mails: ben.alford@amptechpl.com (B.A.); helmut.hugel@rmit.edu.au (H.M.H.)

3 Materials Science and Engineering, CSIRO Preventative Health Flagship, 343 Royal Parade, Parkville, Victoria 3052, Australia; E-Mail: Jo.Caine@csiro.au

* Author to whom correspondence should be addressed; E-Mail: ian.macreadie@rmit.edu.au; Tel.: +61-3-9925-6627; Fax: +61-3-9925-7110.

Academic Editor: Jürg Bähler

Received: 2 March 2015 / Accepted: 3 April 2015 / Published: 17 April 2015

\begin{abstract}
A family of 21 polyphenolic compounds consisting of those found naturally in danshen and their analogues were synthesized and subsequently screened for their anti-amyloidogenic activity against the amyloid beta peptide $\left(\mathrm{A} \beta_{42}\right)$ of Alzheimer's disease. After $24 \mathrm{~h}$ incubation with $\mathrm{A} \beta_{42}$, five compounds reduced thioflavin $\mathrm{T}$ (ThT) fluorescence, indicative of their anti-amyloidogenic propensity $(p<0.001)$. TEM and immunoblotting analysis also showed that selected compounds were capable of hindering fibril formation even after prolonged incubations. These compounds were also capable of rescuing the yeast cells from toxic changes induced by the chemically synthesized $A \beta 42$. In a second assay, a Saccharomyces cerevisiae AHP1 deletant strain transformed with GFP fused to $\mathrm{A} \beta 42$ was treated with these compounds and analyzed by flow cytometry. There was a significant reduction in the green fluorescence intensity associated with 14 compounds. We interpret this result to mean that the compounds had an anti-amyloid-aggregation propensity in the yeast and GFP-A $\beta_{42}$ was removed by proteolysis. The position and not the number of hydroxyl groups on the aromatic ring was found to be the most important determinant for the anti-amyloidogenic properties.
\end{abstract}


Keywords: Alzheimer's disease; Saccharomyces cerevisiae; polyphenols; AHP1; anti-amyloidogenic; danshen

\section{Introduction}

Alzheimer's disease (AD) has been classified as one of the protein misfolding diseases due to the presence of amyloidogenic protein, in particular amyloid beta $\left(A \beta_{42}\right)$ and its tendency to misfold and aggregate into insoluble, toxic amyloid fibrils. Various sizes of $A \beta$ oligomer have been associated with the onset and progression of $\mathrm{AD}[1,2]$. For example, oligomeric forms have been shown to induce synaptic dysfunction [3] and SDS-stable oligomers were found to be neurotoxic [4], whereas $\mathrm{A} \beta$ monomers and mature fibrils are relatively inert $[5,6]$. Therefore, targeting the $A \beta$ oligomerization and aggregation pathway has become a key focus for discovering therapeutics that may be capable of preventing or delaying the onset of $\mathrm{AD}$ [7]. Studies have shown that the anti-parallel $\beta$-sheet orientation of the peptide, and hence the aggregation, could be blocked by compounds that can act as $\beta$-sheet breakers or ligands $[8,9]$.

There is a growing consensus in the literature that the frequently investigated polyphenols could be key molecules for the development of therapeutics or as a part of a prevention strategy for AD [10-14]. Polyphenols are present widely in fruits and vegetables. The chemo-protective effects of (-)-epigallocatechin-3-gallate (EGCG), a polyphenol in green tea, as an anti-aging and cancer prevention agent have been well documented [15-21]. It has been proposed that oxidized EGCG molecules prevent toxicity and dissociation of $\mathrm{A} \beta$ peptide by covalent cross-linking and formation of Schiff bases with free amine groups/residues within the fibrils [22]. Although epidemiological studies have shown that consumption of red wine, coffee, rosemary, curcumin, and many other polyphenols can have a protective effect against Alzheimer's disease and even reverse the cognitive impairment [23], only few studies have investigated the effect of small molecules on the $A \beta_{42}$ aggregation and toxicity in a simpler but powerful model like yeast. This model previously has been proven to be important for its contribution in identification of $\beta$-secretase activity [24] and determining the necessary component for biological activity and function of $\gamma$-secretase [25], as well as autophagic response to A $\beta_{42}$ toxicity [26]. Another microbial model reported by Perez et al. utilizes Escherichia coli to study the inhibition of amyloid production by $A \beta_{42}$ and tau: this microbe has also been employed in polyphenolic compounds [27].

The Chinese herbal medicine danshen (Salvia miltiorrhiza) has been associated with many health benefits. Recent analysis has shown that the presence of both lipid- and water-soluble active phytochemical constituents in danshen can inhibit the formation of $A \beta_{42}$ fibrils (reviewed in [28]). The largest group of plant phenolics in the diet are the hydroxycinnamic acids (HCA), namely caffeic acid, ferulic acid, and chlorogenic acid (reviewed in [29]). Natural polyphenols that are regularly consumed in foods have shown promising therapeutic effects and attracted great research attention [30]. Danshen constituents have also been shown to possess potential therapeutic effects in the treatment of AD in both animal models by attenuating cognitive dysfunction induced by the $A \beta 42$ peptide [31-33] and in tissue culture studies [34-37] due to protection against the toxicity of the amyloid peptide. 
In this work a group of 21 phenolic compounds related to those from danshen and their analogues (mainly hydroxybenzoic acid (HBA) derivatives) were screened for activity against the oligomerization of $A \beta_{42}$. Since the number and position of the hydroxyl moieties attached to the phenyl rings in benzoic acid and cinnamic acid analogs are variable, this allowed the investigation of the role the hydroxyl groups play in the amyloid inhibitory activity of these phenolic acids. Further, in order to explore whether the hydroxyl group possess unique or essential antiamyloidogenic activity in those phenolic acids, various methoxy benzoic and cinnamic acid derivatives were also examined.

\section{Results and Discussion}

\subsection{Inhibitory Effects of Phenolic Compounds on A $\beta_{42}$ Aggregation}

The ability of phenolic compounds to inhibit the formation of $A \beta_{42}$ oligomers and aggregates was monitored by co-incubating freshly prepared $A \beta_{42}$ with phenolic compounds and measuring the Thioflavin T (ThT)-induced fluorescent intensity. Because the colors associated with many of these compounds might interfere with ThT, modulate the fluorescence yield of ThT, and bias the results [38], analyses of these compounds without addition of $A \beta_{42}$ peptide were also included. This allowed adjustment of the baselines and elimination of the effect of color on the photometric readings or quenching of the ThT fluorescence in this assay.

At the baseline $(0 \mathrm{~h})$ the starting fluorescent intensity was significantly lower in a positive control (EGCG) compared with $\mathrm{A} \beta_{42}$ and vehicle buffer $(p<0.01$; Figure 1a). A similar effect was also viewed in the presence of caffeic acid trimers (BA_PG65, BA_PG69), chalcone (BA_PG84), and-to lesser extent - the Benzo[b]furan derivative (BA_PG83) $(p<0.05)$. Benzofuran-based compounds have previously been shown to exhibit potential aggregation and neurotoxicity inhibition effect against $\mathrm{A} \beta 42[39,40]$.

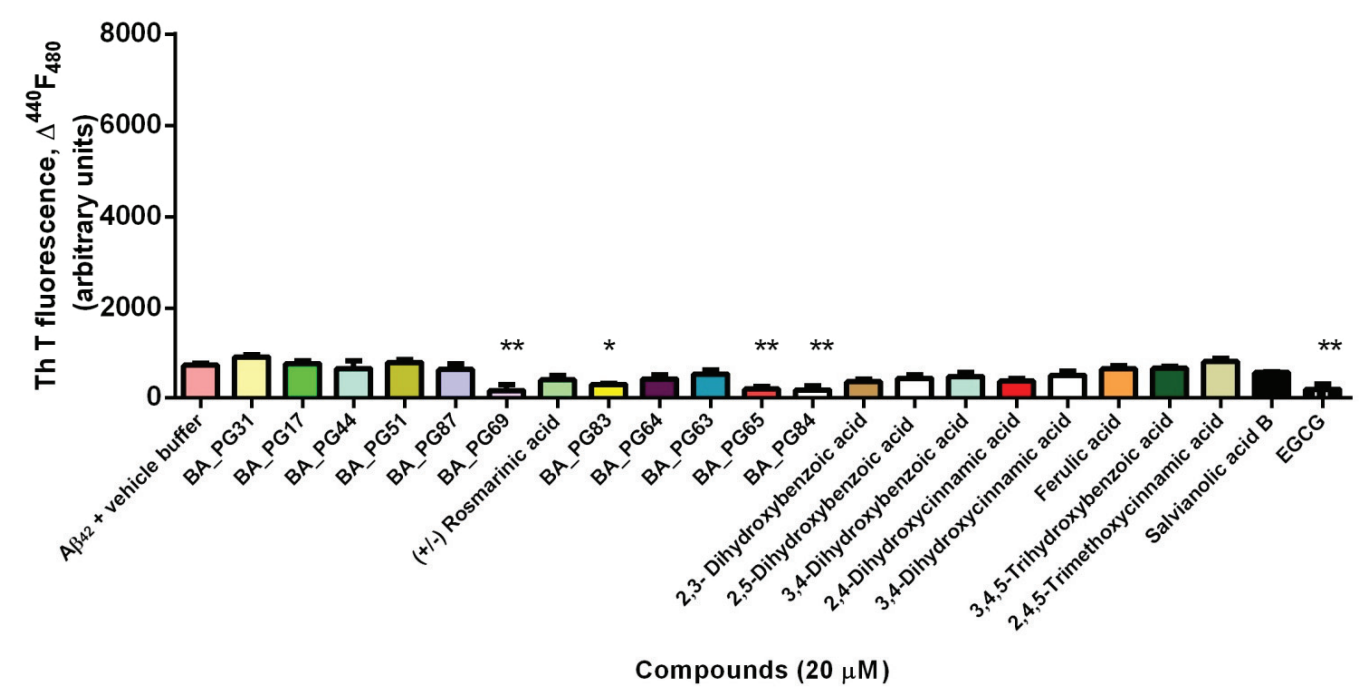

(a)

Figure 1. Cont. 


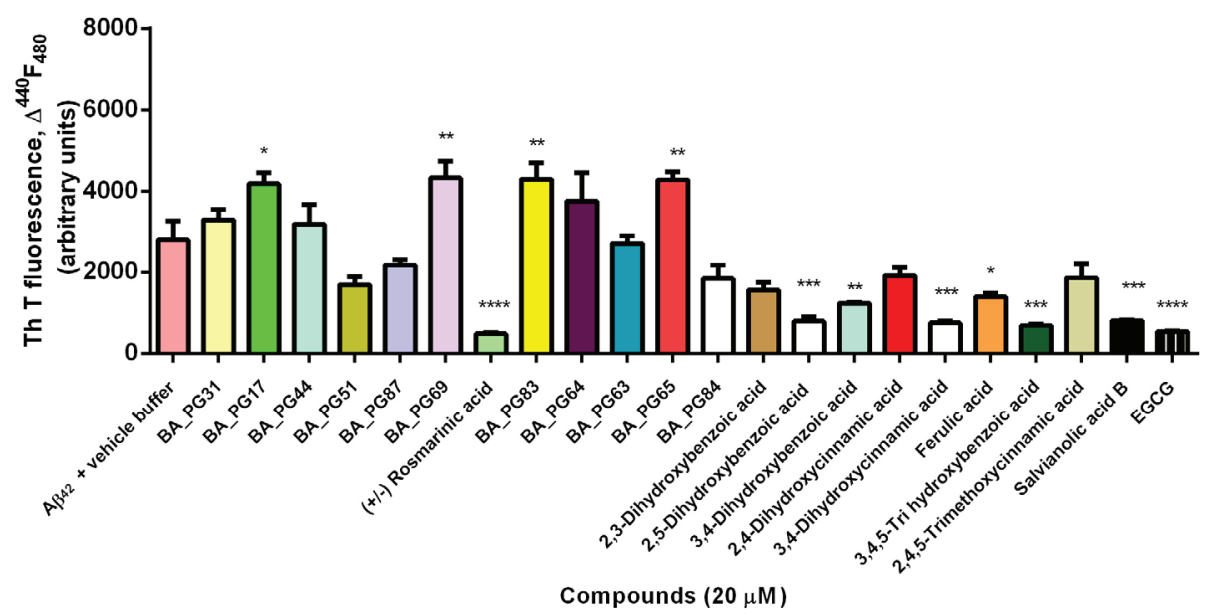

(b)

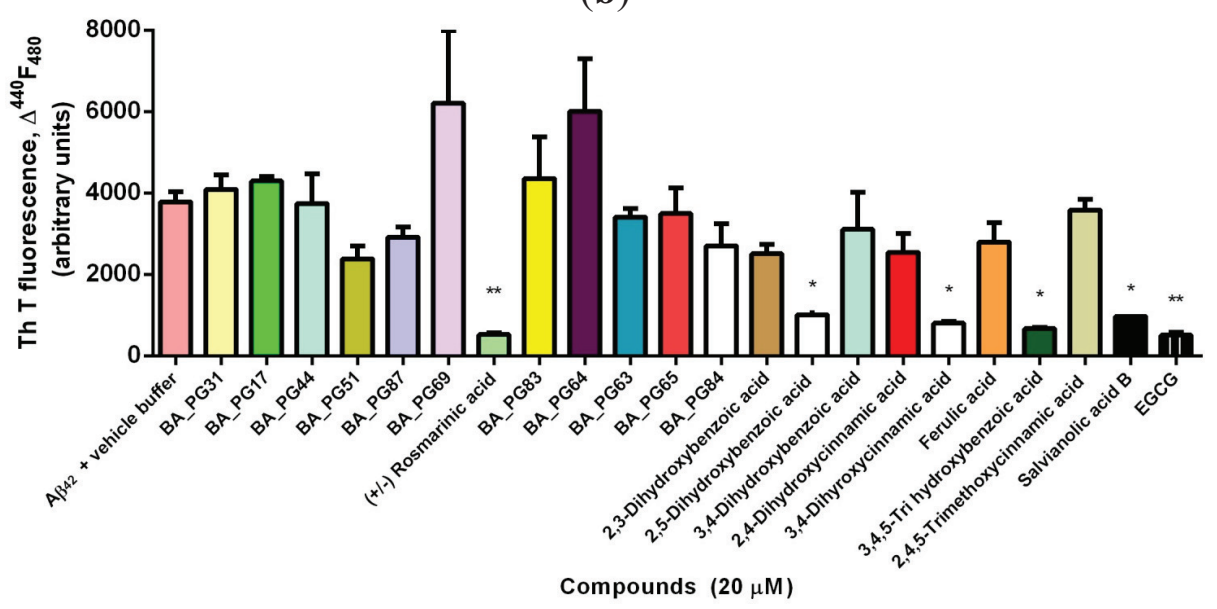

(c)

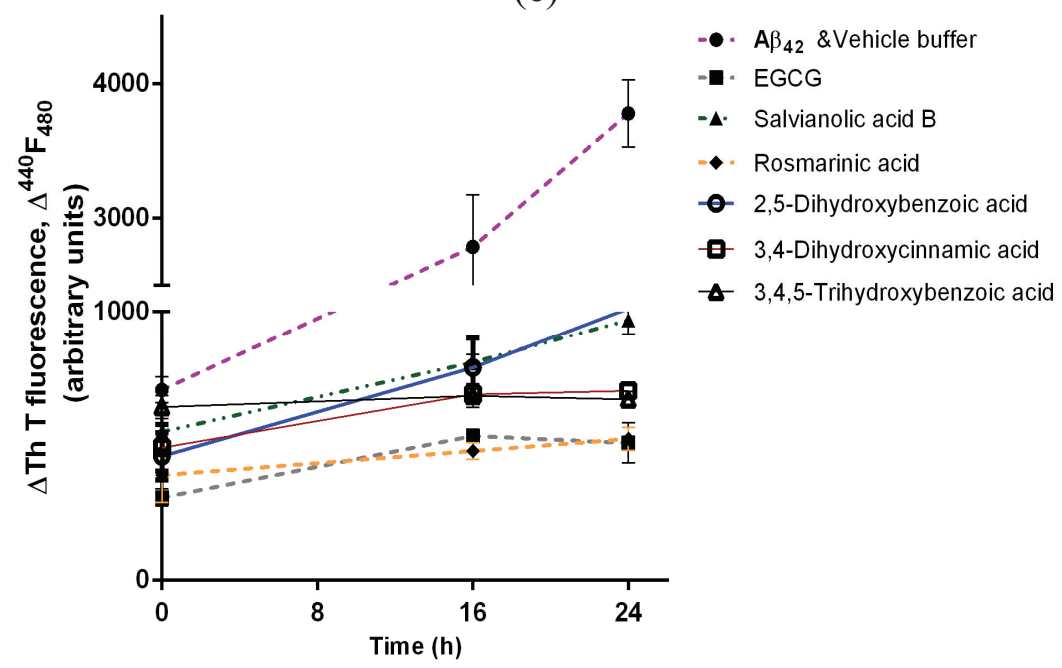

(d)

Figure 1. Amyloid formation assayed by thioflavin $\mathrm{T}$ fluorescence. (a) Fibril formation of $\mathrm{A} \beta_{42}$ and the associated increase in in situ ThT fluorescence in presence and absence of compounds were measured at $0 \mathrm{~h}$ (baseline) (b) after $16 \mathrm{~h}$ (c) and after $24 \mathrm{~h}$ incubation; (d) Selected phenolic compounds that resulted in a significant anti-amyloidogenic property compared with the positive control (EGCG) and negative control ( $\mathrm{A} \beta_{42}$ \& vehicle buffer) determined by ThT measured at 0,16 , and $24 \mathrm{~h}$ after incubation with chemically synthesized $\mathrm{A} \beta 42$. Significant differences are indicated: $* p<0.05 ; * * p<0.01 ; * * * p<0.005 ; * * * * p<0.001$. 
After $16 \mathrm{~h}$ incubation, ferulic acid and 3,4-DHBA reduced the ThT, but this effect was transient and was not observed after $24 \mathrm{~h}$ incubation (Figure 1b). Ferulic acid has been shown [41] to disrupt the $A \beta_{42}$ preformed fibrils through aromatic hydrophobic interactions and hydrogen bonding with the amyloid peptide.

After $24 \mathrm{~h}$ co-incubation of compounds with A $\beta 42$, rosmarinic acid, similar to EGCG $(p<0.001)$, exerted the most potent inhibitory effect on peptide aggregate formation (Figure 1c). Other compounds that showed aggregation inhibition capacity were 2,5-DHBA (gentisic acid), 3,4-DHCA (caffeic acid), 3,4,5-THBA (gallic acid), and salvianolic acid B ( $p<0.005)$. 3,4-DHBA also significantly reduced the aggregation propensity of $A \beta_{42}$ compared with the control sample $(p<0.01)$. On the other hand, caffeic acid trimers BA_PG65 and BA_PG69, as well as compounds BA_PG83 $(p<0.01)$ and BA_PG17 $(p<0.05)$, significantly contributed to the increased ThT associated fluorescence after $24 \mathrm{~h}$ co-incubation with chemically synthesized $A \beta_{42}$. Further, the results suggest that these compounds accelerated the aggregation and fibril formation capacity of the peptide compared with the control sample (Figure 2a). Five compounds lowered the fluorescent intensity, indicating their capability in slowing aggregation and fibril formation (ThT negative). These were rosmarinic acid, 2,5-DHBA, 3,4-DHCA, 3,4,5-THBA (gallic acid), and salvianolic acid B $(p<0.05)$ (Figure 1d). The kinetic effect of EGCG on $A \beta_{42}$ fibrillogenesis inhibition was unlike that of the other compounds. EGCG interacts early with $A \beta_{42}$ and dissociates oligomer formation in a sustainable manner.

The therapeutic effect of many polyphenols has been attributed to the presence of aromatic rings, namely phenyl rings and hydroxyl groups, which result in decreased fibril formation [42]. The effect of these aromatic residues is attributed to their hydrophobic interactions in the $\pi$-stacking interaction with aromatic amino acids in the amyloid, and halting the $\beta$-amyloid self-assembly process that leads to oligomerization $[43,44]$. Ono et al. [45] have indicated that the greater the number of hydroxyl groups present, the higher the anti-amyloidogenic activity. Our results show that the number of hydroxyl moieties attached to the phenyl ring is not the major determinant. After analyzing the positional isomers, it became clear that the position of the hydroxyl moieties on the aromatic ring is the main reason for their inhibitory potency. Overall, the effect of these aromatic residues in polyphenols is due to their ability to prevent transition of $\alpha$-helix conformation to $\beta$-sheet and therefore fibril formation [46]. Also, it became apparent that the positions of the hydroxyl groups may be more important than their numbers in the structure for their optimum biological activity. Among the compounds tested, simple benzoic acid derivatives identified by the number and positions of hydroxyls on the aromatic ring displayed different anti-oligomerization activities. At the baseline both 3,4-DHBA and 2,5-DHBA isomers [47] (refer to Figure 2 for chemical structures) were active in hindering oligomer and fibril formation, and after $24 \mathrm{~h}$ incubation only 2,5-DHBA remained inhibitory. Therefore, the position of hydroxyl groups on the 2,5-DHBA isomer contributed to the anti-oligomerization potency compared with other DHBA isomers and trihydroxybenzoic acid (THBA) (Figure 2a). 2,5-DHBA, however is known not to detoxify existing amyloid fibrils [47]. 3,4,5-THBA (gallic acid), unlike 2,3, 2,5-, and 3,4-DHBA, was reported by LeVine et al. [47] to stabilize biotinyl-A $\beta_{42}$ oligomers and block their dissociations in the presence of active dissociators. 

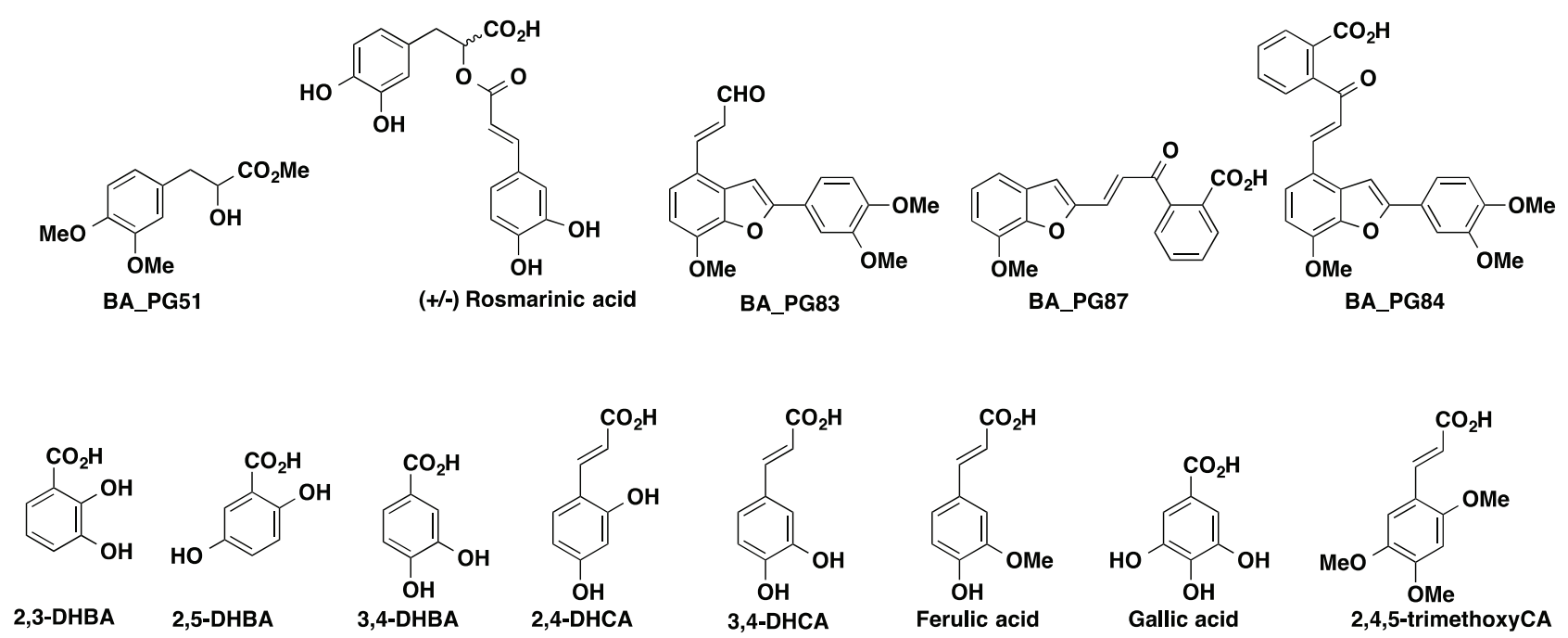

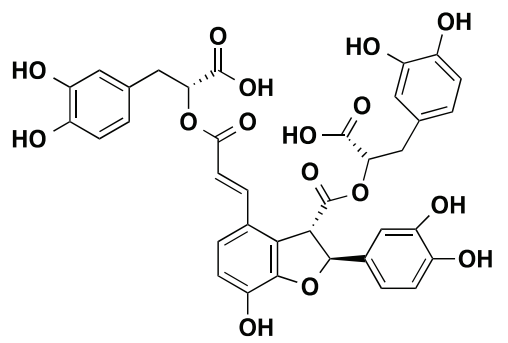

Salvianolic acid B

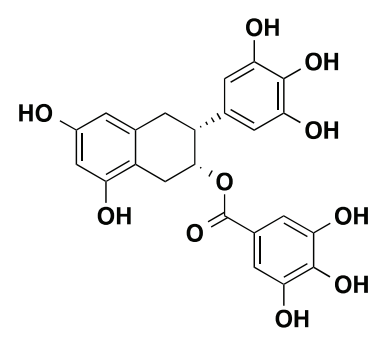

(-)-Epigallocatechingallate (EGCG)<smiles>O=C(O)c1cc(O)ccc1OC1Cc2cc(O)cc(O)c2CC1c1cc(O)ccc1O</smiles>

EC analogue

(a)

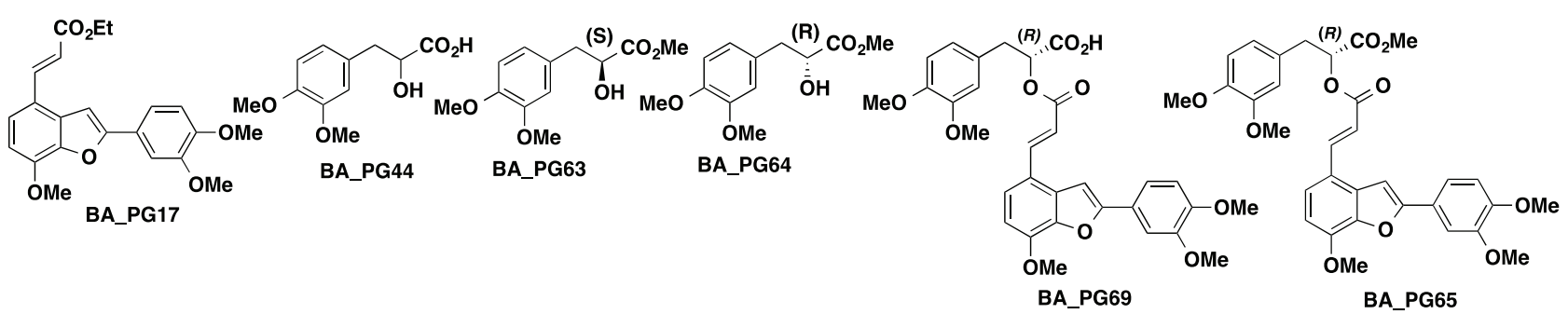

(b)

Figure 2. Chemical structures of analyzed polyphenolic compounds. (a) Compounds that reduced ThT associated fluorescent similar to EGCG; (b) compounds that were not found to be potent inhibitors of amyloid aggregation.

The time comparisons of the data in Figure 1b,c suggests that the greater lipophilicity of the methoxy ether and ester derivatives BA-PG69 and BA-PG65 of (+/-) rosmarinic acid did not enhance $\mathrm{A} \beta_{42}$ aggregation in the yeast model. The $24 \mathrm{~h}$ incubation of 2,4,5-trimethoxycinnamic acid (THCA) showed a similar lack of potency with time. This work therefore raises the question whether the hydrogen bonding nature and the position of the hydroxyl groups, shown in the EC analogue structure in Figure 2a, may exhibit potent anti-amyloidogenic properties. Replacing - $\mathrm{OH}$ groups with methoxy on inositol has been shown to stabilize the protofibrils in vitro and attenuate the spatial memory impairments in mice model of AD [48]. Other compounds-BA_PG44, BA_PG51, BA_PG87, BA_PG63, and BA_PG64 - did not show similar potency to EGCG (Figure 2b). EGCG has been shown to redirect amyloidogenic peptide into unstructured, non-toxic and off-pathway oligomers [49]. 


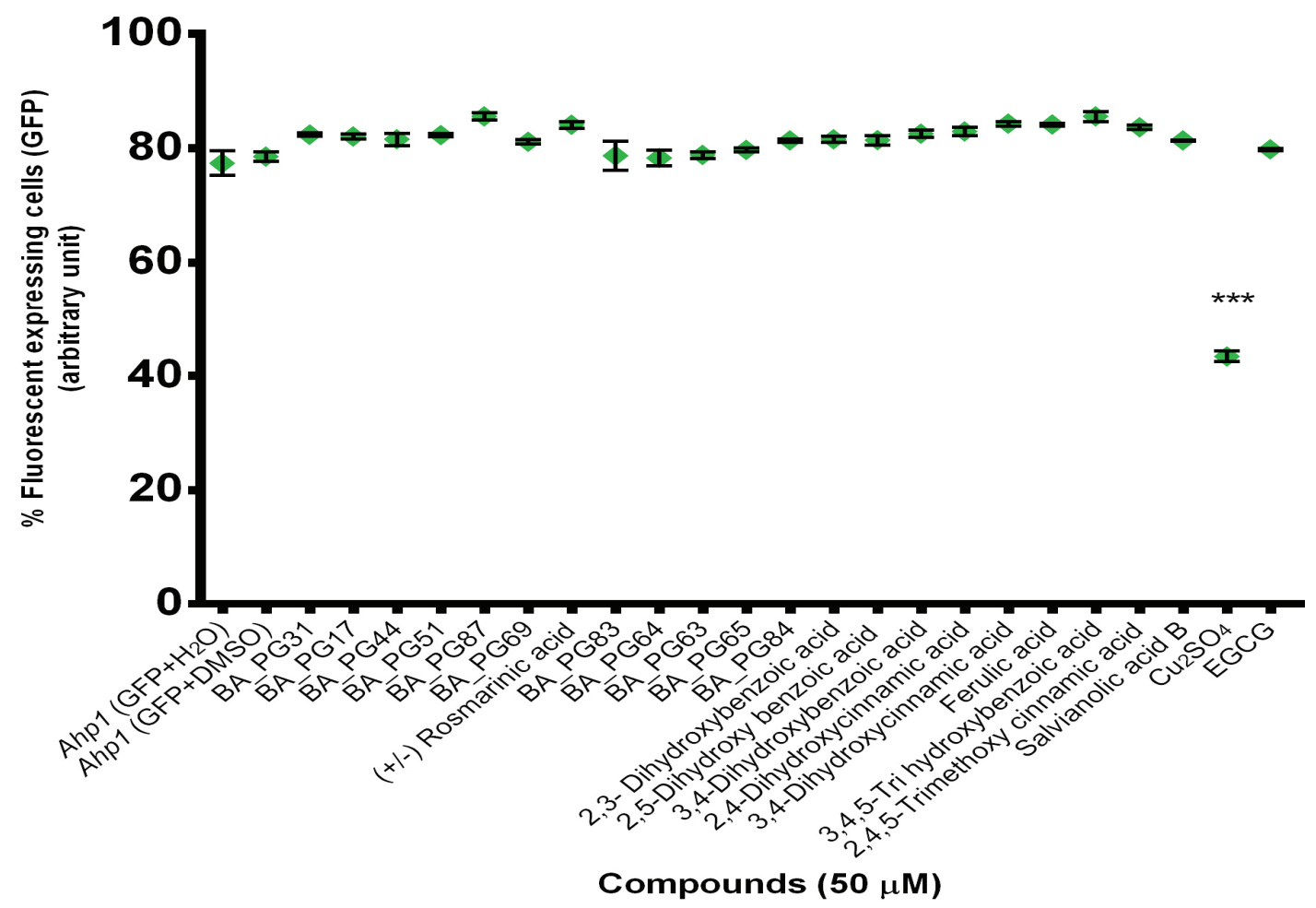

(a)

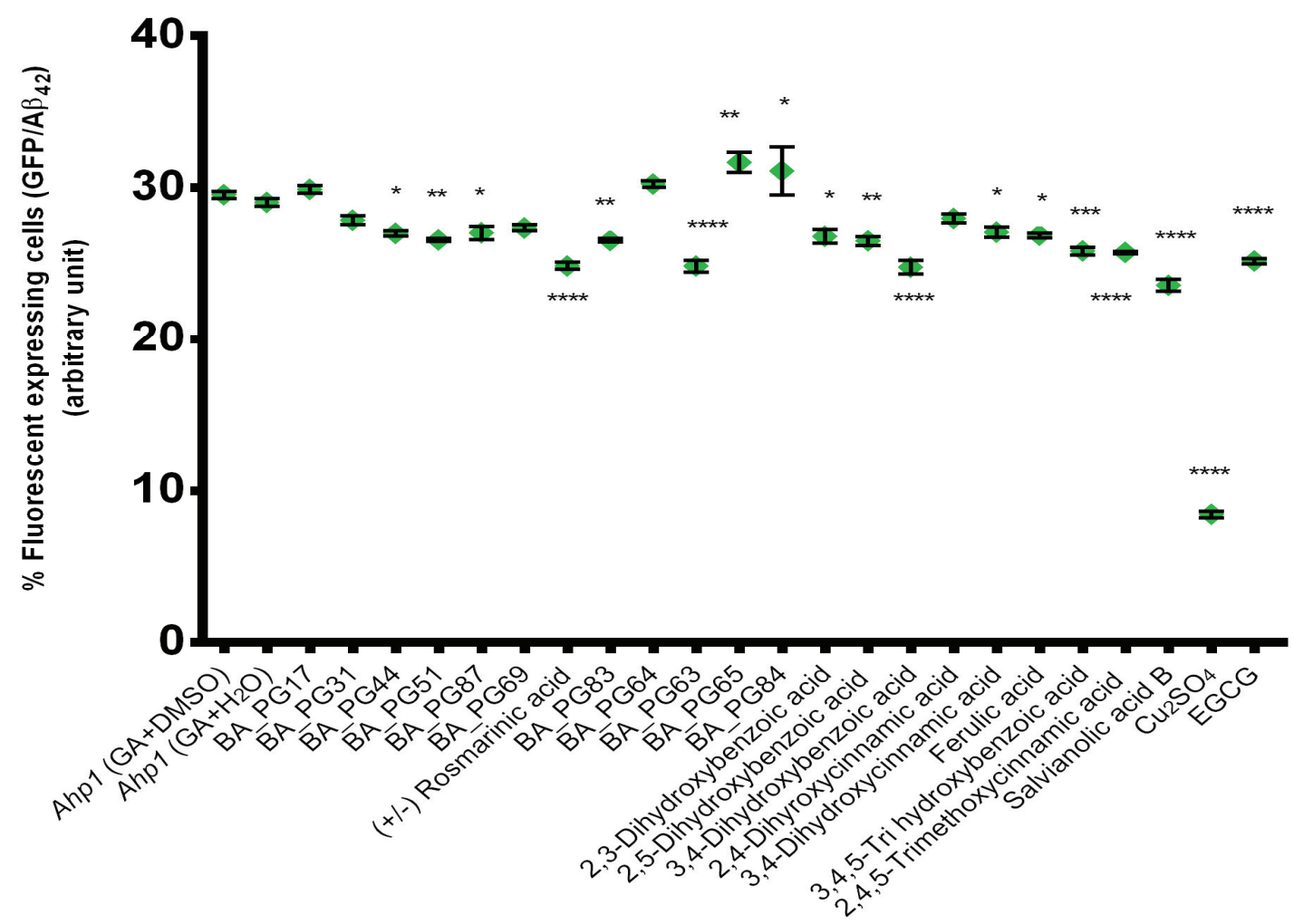

Compounds $(50 \mu \mathrm{M})$

(b)

Figure 3. (a) Flow cytometry analysis of transformants of $A h p l$ strain with GFP and (b) GFP-A $\beta_{42}$ in the presence of polyphenolic compounds. 
High throughput in vivo screening of compounds that inhibit aggregation of $\mathrm{A} \beta_{42}$ using green fluorescent protein (GFP) fusion has been reported previously [50-52]. Therefore, compounds were screened for their effect on the reduction or increase in fluorescence due to aggregation of $A \beta_{42}$ in AHP1 deletant strain $S$. cerevisiae transformants expressing GFP-A $\beta_{42}$. The alkyl hydroperoxide reductase protein (Ahplp) is a thiol-specific peroxiredoxin that provides protection against reactive oxygen species (ROS) [53,54]. Using this mutant strain Ahpl should allow identification of those compounds that can provide protection against oxidation and those capable of inhibition of amyloid aggregation in the GFP-A $\beta_{42}$ fusion-associated fluorescence assay. This screening is based on the percentage of fluorescence emission from the correct folding of GFP as a reporter for $A \beta_{42}$ aggregation in the presence of compounds. The GFP fusion system used in this study has been described previously [51]. This GFP-A $\beta_{42}$ fusion results in the green fluorescent being visible in punctuate patches. In the GFP expression alone, the GFP is distributed uniformly throughout the cell. The green fluorescence associated with GFP alone was very strong and present in most cells compared with the GFP-A $\beta_{42}$ fusion. In fact, in vehicle buffer (DMSO) control samples the GFP florescence was observed in $\sim 80 \%$ of cells $(78.5 \pm 1.4)$ (Figure $3 \mathrm{a}$ ). This level did not change significantly in the presence of $50 \mu \mathrm{M}$ phenolic compounds. The selected ThT negative compounds also reduced the fluorescence associated with the GFP-A $\beta_{42}$ fusion (Figure $3 b$ ).

Fourteen compounds reduced the green fluorescence associated with GFP-A $\beta_{42}$ fusion (Figure $3 b$ ). Reduction of green fluorescence has been reported to be the result of autophagy and proteolysis response [55]. Rosmarinic acid, salvianolic acid B, BA_PG63, 2,4,5-trimethoxyCA, 3,4,5-THBA, and 3,4-DHBA reduced the fluorescence level similar to EGCG $(p<0.001)$. Compounds such as BA_PG65 $(p<0.01)$ and BA_PG84 $(p<0.05)$ increased the green fluorescence associated with GFP-A $\beta 42$ fusion and also showed immediate anti-oligomerization properties in the ThT assay (Figure 1a). Other compounds such as BA_PG44, BA_PG87, BA_PG51, and BA_PG63 did not show high anti-oligomeric potency when tested by the ThT assay (Figure 1a), whereas they significantly decreased the green fluorescence associated with GFP-A $\beta_{42}$ fusion in the yeast model (Figure $3 b$ ). This further indicates that the effect of these compounds on $A \beta_{42}$ aggregation could be different in in vivo biological systems relative to the in vitro systems due to interactions with other cellular components and mechanisms.

\subsection{Protection Effect of Selected Inhibitors against the Cytotoxicity of $A \beta_{42}$}

The cytotoxicity effect of $5 \mu \mathrm{M}$ hexafluoroisopropanol (HFIP) pretreated $\mathrm{A} \beta_{42}$ [56] and the protection of the five selected phenolic compounds $(50 \mu \mathrm{M})$ were tested on $C$. glabrata cells. The survival rate of yeast cells in the presence of $A \beta 42$ was only $\sim 10 \%$ of the untreated control sample (Figure 4). All of the selected phenolic compounds were capable of inhibiting toxicity to the C. glabrata cells when compared with the control. Salvianolic acid B $(p<0.001)$, gentisic acid, gallic acid, and caffeic acid $(p<0.005)$ were the most effective (Figure 3 ). 


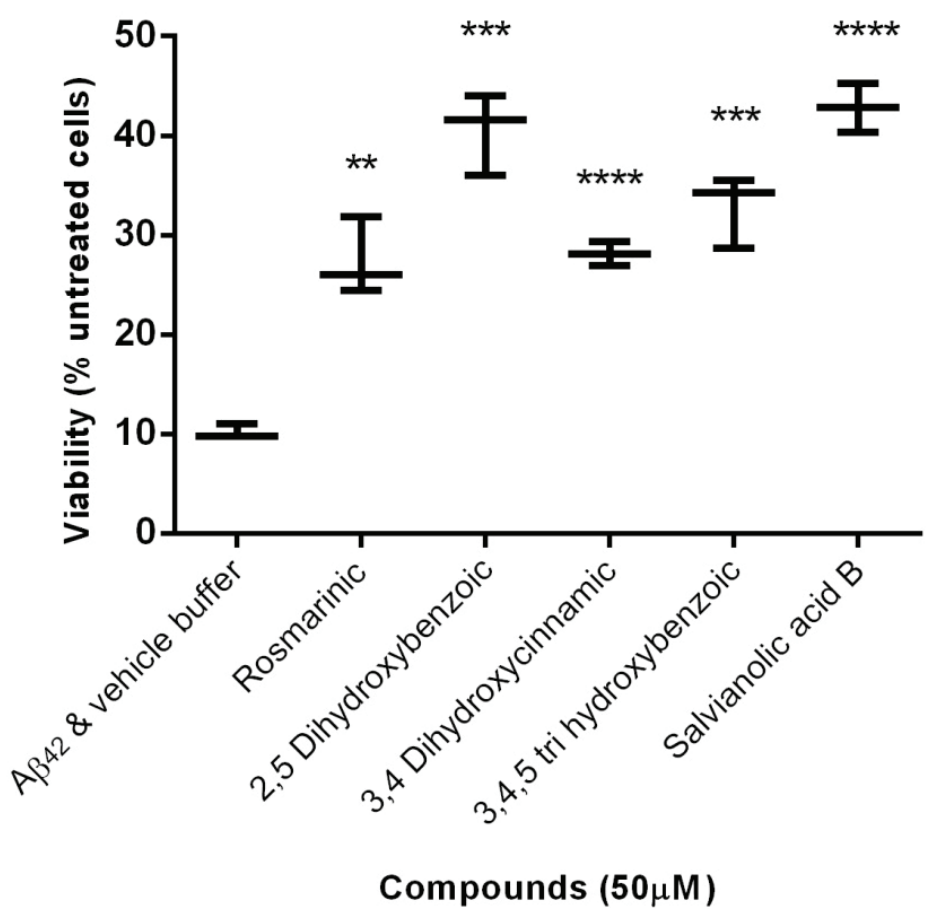

Figure 4. Cytotoxicity effect of freshly prepared HFIP pretreated $A \beta_{42}$ peptide $(5 \mu \mathrm{M})$ on C. glabrata cells.

It should be noted that a synthetic $A \beta_{42}$ peptide was utilized for the cytotoxicity assay and according to previous reports, the oligomers formed by synthetic $A \beta_{42}$ are less stable than naturally occurring oligomers [57]. Endogenous $A \beta$ has also been shown to be more potent than synthetic $A \beta_{42}$ [58]. Despite these dissimilarities, synthetic $A \beta_{42}$ peptide is used widely for the identification of anti-amyloidogenic compounds [59-62]. It should therefore be expected that the biological potency of selected chemicals on inhibiting the aggregation of $A \beta_{42}$ oligomers may not be similar under different conditions. The mechanisms by which the selected compounds rescued cells from $\mathrm{A} \beta 42$ oligomer toxicity could be explained by two distinct pathways. Firstly, the compounds may not be cell-permeable and are attaching to the cell wall and forming a bond with the surface of the yeast, thereby limiting $\mathrm{A} \beta_{42}$ contact and association and secondly, the compounds generate nontoxic $A \beta_{42}$ forms with no cellular toxicity.

\subsection{Selected Compounds Do not Inhibit A ${ }_{42}$ Oligomer Formation (TEM)}

To further explore the effects of the selected ThT negative phenolic compounds (Figure 1c) on amyloid aggregation and fibril formation, morphological changes during 7 day incubation of $A \beta_{42}$ peptide in the presence of these five selected compounds were examined by TEM. A control sample of chemically synthesized $A \beta_{42}$ peptide with only the addition of vehicle buffer was analyzed for morphological comparison.

The control $A \beta_{42}$ sample resulted in highly ordered fibrillar structures (Figure 5a). Although none of the compounds completely prevented aggregation, the extent of protofibril and fibril formation varied in the presence of different compounds. Structures like sheets, globular, and short or long fibrils were formed as a result of the affect of the compounds on the $A \beta_{42}$ conformation. 

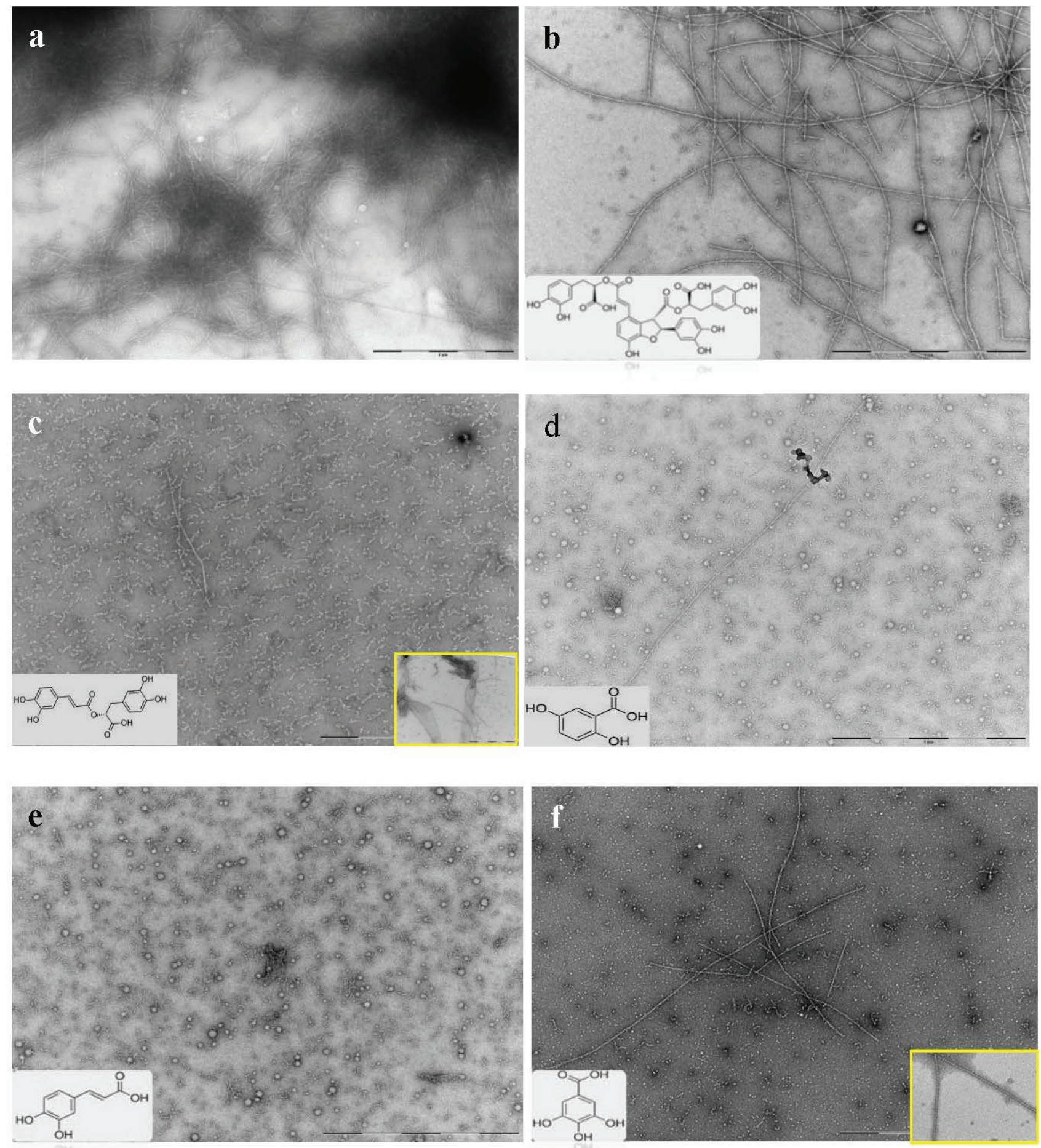

Figure 5. TEM micrograph of $A \beta_{42}$ co-incubated with selected compounds. (a) Morphological effects of selected compounds on chemically synthesized $A \beta_{42}$ aggregation was investigated and compared with the control sample. (b) Micrograph of chemically synthesized $A \beta_{42}$ in presence of salvianolic acid B; (c) rosmarinic acid; (d) 2,5-DHBA (gentisic acid); (e) 3,4-DHCA (caffeic acid); and (f) 3,4,5-THBA (gallic acid). Arrows show micelle (globular) structures, protofibrils, and fibrillar species of $A \beta 42$. A micrograph showing other conformational species of peptide formed by the compound is highlighted in the yellow box. The structure of each compound is also shown on the micrograph. (Scale bars $=200 \mathrm{~nm}$ ). 
Salvianolic acid B resulted in the formation of high molecular weight (HMW) species including protofibrils and mature amyloid fibrils. The fibrils were well separated and dispersed compared with the control sample (Figure 5b). Rosmarinic acid, on the other hand, presented a potency of aggregation inhibition but prolonged incubation resulted in formation of oligomers, protofibrils, long fibrils, and clusters of short fibrillar structures that were merged into sheet-like structures (Figure 5c). In the presence of 2,5-DHBA (gentisic acid) (Figure 5d), micelle-like structures [63] along with many protofibrils became visible. However, few fibrillar structures that were very long in length were detected. Caffeic acid also formed spherical micelle-like species (Figure 5e). The globule structures presumably represented caffeic acid microdroplets in which $A \beta_{42}$ had deposited and begun to aggregate. After 7 days' co-incubation, caffeic acid proved to be a good ligand for the $A \beta_{42}$ peptide, preventing extensive aggregation and fibril formation. 3,4,5-THBA (gallic acid; Figure 5f) resulted in the formation of only a few very long, twisted fibrils. Both 3,4-DHCA and 3,4,5-THBA resulted in the formation of amorphous and spherical structures that are known to be non-toxic, although the exact molecular mechanism underpinning their inhibitory effect in not clear at this point. It indicated, however, that a direct binding of these molecules with intrinsically disordered $A \beta_{42}$ promotes their assembly.

One possible explanation for the detection of a high level of fibrillar structures in the presence of salvianolic acid B and rosmarinic is that these two compounds are capable of accelerating fibril formation after prolonged incubation, resulting in lesser amounts of toxic soluble oligomer formation. Another possible explanation is that these selected ThT negative compounds competitively bind to the $\beta$-sheet site of the amyloid fibrils resulting in the inhibition or a reduction in the ThT interactions with these active sites along the length of the fibrils, causing a lower fluorescent emission associated with ThT [38].

\subsection{PAGE and Western-Blot of A $\beta_{42}$ Co-Incubated with Selected Potent Compounds}

The selected phenolic compounds were investigated for their capacity to prevent oligomeric $A \beta_{42}$ formation after prolonged incubation. SDS-PAGE of the A $\beta_{42}$ conformers that formed over 7 days; incubation in the presence of ThT negative compounds were analyzed by silver staining and Western blot using WO2 monoclonal antibody against the $\mathrm{A} \beta$ peptide.

Silver staining confirmed the presence of $\mathrm{A} \beta_{42}$ peptide in all of the samples but despite being a sensitive technique it did not show differences between treatment and control samples (Figure 6a). $\mathrm{A} \beta_{42}$ peptide was detected for all experimental samples (Figure 6a; lane 2-6) and control samples (Figure 6a; lane 1 and 7). The band intensity for monomers, dimers, and tetramers was similar in both silver staining and immunoblot analysis. However, the resolution of oligomeric species was very low, possibly due to gel smearing, which prevented quantification of individual sizes of oligomers within this range (Figure 6a).

The immunoblotting assay revealed that all of the compounds (Figure 6b; lanes 1-5) appear to be hindering fibrillogenesis when compared with the untreated control (Figure 6b; lane 6). Freshly prepared $A \beta_{42}$ only formed monomeric and dimeric structures $(<14 \mathrm{kDa})$, with no aggregation detected (Figure $6 \mathrm{~b}$; lane 7). In monomeric form (4.5 kDa), $\mathrm{A} \beta_{42}$ peptide is considered to be nontoxic [64]. However, nucleation can trigger self-assembly of these monomeric species of $A \beta_{42}$ into oligomers, large intermediate aggregates, and eventually fibrillar aggregates [65,66]. Low molecular weight 
(LMW) oligomer species, distinguished by their solubility and size ( $>14 \mathrm{kDa})$, appear between monomeric and insoluble fibrils [67]. The level of oligomeric peptides was very high in the presence of salvianolic acid B (Figure 6b; lane 1). These results indicate the presence of high molecular weight species of oligomers and protofibrils, especially at $>70 \mathrm{kDa}$ (Figure $6 \mathrm{~b}$; lane 1). The oligomeric detection in the untreated control, on the other hand, was very low, demonstrating acceleration in formation of insoluble fibrils (Figure 6b; lane 6). All of the ThT-negative compounds were apparently capable of hindering the fibril formation but were not able to prevent complete oligomerization. Longer incubation times resulted in a slower aggregation propensity of the $A \beta_{42}$ peptide in the presence of these selected ThT-negative compounds. These results suggest that selected compounds might act as a ligand for the $\beta$-sheet regions on the $A \beta 42$, hence delaying the association of these regions for aggregation and therefore interfering with oligomerization and the fibril formation process.

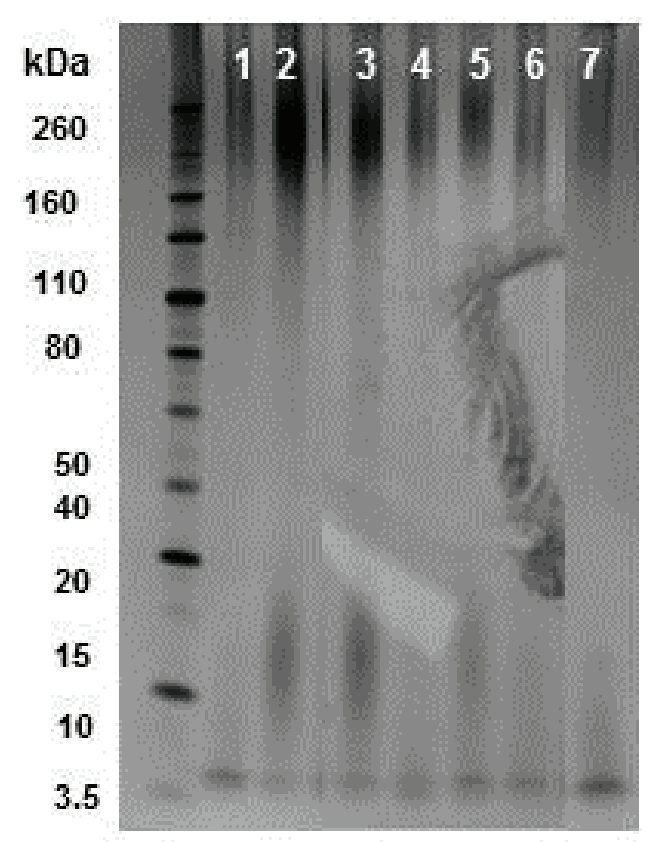

(a)

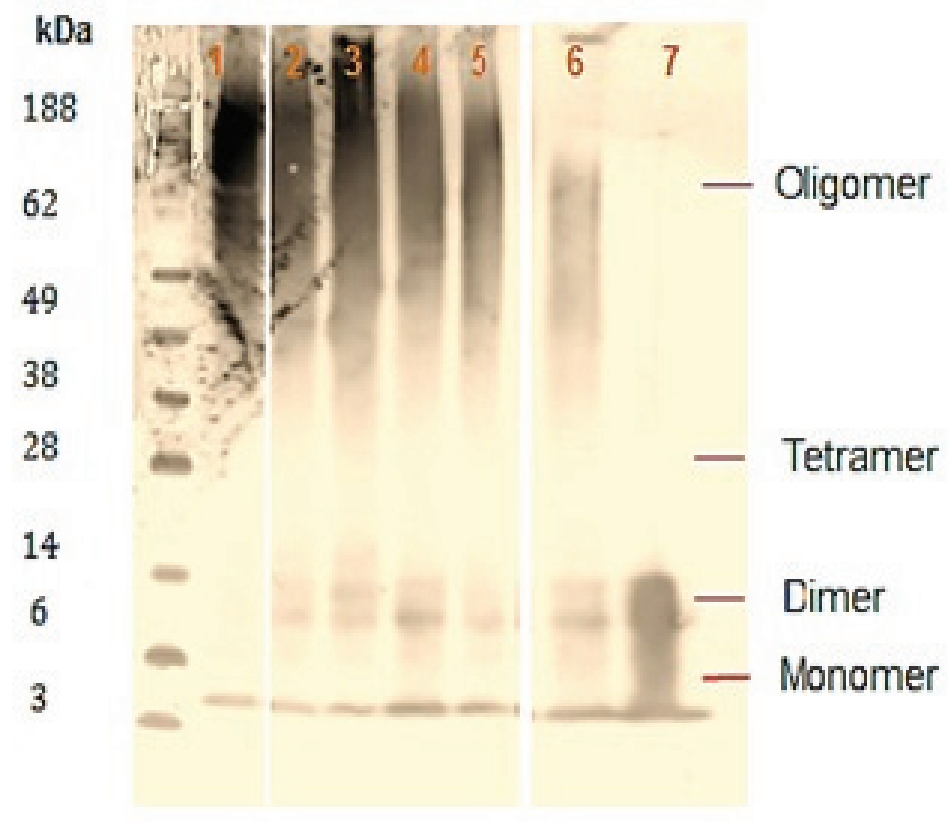

(b)

Figure 6. SDS-PAGE analyses of $A \beta_{42}$ conformers in the presence and absence of compounds. (a) Peptide solutions co-incubated with the selected phenolic compounds were fractioned by SDS-PAGE electrophoresis (4\%-12\% Bis-Tris gel). One hundred nanograms of each $A \beta_{42}$ sample were analyzed by silver staining. Samples are vehicle buffer control and $\mathrm{A} \beta_{42}$ (lane 1), salvianolic acid $\mathrm{B}$ (lane 2), rosmarinic acid (lane 3), 2,5-DHBA (lane 4), 3,4-DHCA (lane 5), 3,4,5-THBA (lane 6), and freshly prepared A $\beta_{42}$ (lane 7). Lane M contains molecular weight marker. Half a microgram of each $A \beta_{42}$ sample (from TEM experiment) was also analyzed by immunoblotting (Section 2.4) using anti-A $\beta$ WO2 antibody; (b) $0.5 \mu \mathrm{g}$ of each $\mathrm{A} \beta_{42}$ sample (from TEM experiment) was also analyzed by immunoblotting using anti-A $\beta$ WO2 antibody. Samples are salvianolic acid B (lane 1), rosmarinic acid (lane 2), 2,5-DHBA (lane 3), 3,4-DHCA (lane 4), 3,4,5-THBA (lane 5), vehicle buffer control and $A \beta_{42}$ (lane 6), and freshly prepared $A \beta_{42}$ (lane 7). Molecular weight markers are shown in lane $\mathrm{M}$. 


\section{Experimental Section}

\subsection{Yeast Strains}

Saccharomyces cerevisiae BY4743 and the AHP1 deletion (AHP1::URA3) mutant derived from BY4743 were used for the transformation of GFP-A $\beta_{42}$ and GFP plasmids and flow cytometry. For the toxicity assay the Candida glabrata ATCC90030 strain was used.

\subsection{Compound Library of Polyphenol Derivatives (21 Compounds)}

A compound library consisting of 21 phenolic compounds and their analogues was synthesized. Syntheses of some of these compounds have been explained by Alford (2013) [68]: BA_PG31, BA_PG17, BA_PG44, BA_PG51, BA_PG87, BA_PG69, (+)-rosmarinic acid, BA_PG83, BA_PG64, BA_PG63, BA_PG65, BA_PG84, 2,3-, 2,5-, and 3,4-dihydroxybenzoic acid (DHBA), 2,4-, and 3,4-dihydroxycinnamic acid (DHCA), ferulic acid, 3,4,5-tri-hydroxybenzoic acid (gallic acid), and 2,4,5-trimethoxy cinnamic acid. The chemical structures of BA_PG compounds with significant inhibition propensity have been provided (Figure $2 \mathrm{a}$ ).

\subsection{Flow Cytometry Analysis of Compound-Treated Transformants}

Fluorescence associated with the GFP fluorescent in yeast was measured and quantified by flow cytometry experiments. Cells for all of the following experiments were analyzed using a FACScan flow cytometer (BD FACS Canto ${ }^{\mathrm{TM}}$ II, Becton-Dickinson, Franklin Lakes, NJ, USA) and the captured files were saved as FCS3 and processed using the free trial version of WEASEL ${ }^{\text {TM }}$ software (WEHI, Parkville, VIC, Australia).

The $S$. cerevisiae AHPl deleted strain (Ahpl) was transformed with plasmids encoding green fluorescent protein (GFP) and GFP fused to the C-terminus of $\mathrm{AB}_{42}$ (GA) using a kit (EZ-Yeast ${ }^{\mathrm{TM}}$ transformation Kit-MP, Biomedicals, Santa Ana, CA, USA). Cells were then plated on YNB without uracil for selection of transformants. Both constructs are under constitutive expression and have a URA3 selectable marker. Prior to treatment with the compounds, transformed yeasts with the vectors were grown in selective media to exponential phase with gentle agitation $\left(30{ }^{\circ} \mathrm{C} ; 200 \mathrm{rpm}\right)$. When the opacity of the culture reached $\mathrm{OD}_{600 \mathrm{~nm}}$ of 0.8 , around $150 \mu \mathrm{L}$ of culture was transferred into a 96 -well microtiter plate. All of the test compounds were dissolved in dimethyl sulfoxide (DMSO) solvents and were pre-screened for inherent fluorescence using the GFP transformants. Compounds were then added to the GA transformants at a final concentration of $50 \mu \mathrm{M}$. Control samples of pure DMSO were included as the negative control and growth was continued for an additional $6 \mathrm{~h}$ at $30^{\circ} \mathrm{C}$ with shaking. Around $300 \mu \mathrm{L}$ of the suspension was transferred into a flow cytometry tube. For measuring cell death, $3 \mu \mathrm{L}$ of propidium iodide (PI) solution $(100 \mu \mathrm{g} / \mathrm{mL}$ stock) was added to the flow tube to achieve the final concentration of $1 \mu \mathrm{g} / \mathrm{mL}$. After addition of PI to the cells, the samples were incubated in the dark for $30 \mathrm{~min}$ at room temperature or for $20 \mathrm{~min}$ at $37^{\circ} \mathrm{C}$. Around 20,000 cells were counted in each sample and the percentage of cells exhibiting red and green fluorescence were recorded on BD FACS Canto ${ }^{\mathrm{TM}}$ II flow cytometer. The GFP green fluorescence level was measured using a FITC 530/30 filter (494/519-nm excitation/emission). Red fluorescence due to PI staining was measured with a PerCP 
670LP filter (488/617-nm excitation/emission). Data were recorded and saved as FCS3 files and were analyzed by WEASEL ${ }^{\mathrm{TM}}$ (WEHI, Parkville, VIC, Australia). All compounds were analyzed in triplicate. Significant differences are indicated: $* p<0.05 ;{ }^{* *} p<0.01 ; * * * p<0.005 ; * * * * p<0.001$.

\subsection{Synthetic A $\beta_{42}$ Peptide Preparation and Analysis}

The synthetic $A \beta_{42}$ peptide was purchased from Keck laboratories (Yale University, New Haven, $\mathrm{CT}$, USA) in the form of a lyophilized powder stored at $-20^{\circ} \mathrm{C}$. According to Keck laboratories, the peptide was synthesized and purified using tBOC chemistry with DCC and HOBT coupling reagents. All solvents used for the preparation of $A \beta_{42}$ solutions were pre-filtered and centrifuged to minimize the presence of any debris that can induce aggregation of the peptide.

Peptide preparation was done according to the protocol of Ryan et al. [69]. Briefly, $20 \mathrm{mg}$ of peptide was dissolved in $40 \mathrm{~mL}$ of $10 \% \mathrm{NH}_{4} \mathrm{OH}$ to a final concentration of $0.5 \mathrm{mg} / \mathrm{mL}$ solution (w/v). The solution was then left at room temperature for $10 \mathrm{~min}$ and then sonicated for $5 \mathrm{~min}$. This solution was then freeze dried and the peptide film (peptide pellet) was stored at $-80{ }^{\circ} \mathrm{C}$ until use. Peptide concentration was determined using a quartz cuvette at $\mathrm{A}_{214 \mathrm{~nm}}$ reading. For toxicity assays oligomeric $\mathrm{A} \beta_{42}$ was dissolved in 1,1,1,3,3,3-hexafuoro-2propanol (HFIP) according to the method described by Bharadwaj et al. [55].

\subsection{Thioflavin T (ThT) Fluorescence Assay}

Thioflavin $\mathrm{T}$ dye is usually used to monitor the aggregation process of $\mathrm{A} \beta$ peptide and quantify the extent of amyloid fibrils formation; this process has been described previously [70-72]. Two-millimolar stock solutions of all inhibitors were made in DMSO and stored at $4{ }^{\circ} \mathrm{C}$ or on ice. The starting ratios of $\mathrm{A} \beta$ to compounds were $1: 1$ (20 $\mu \mathrm{M}$ of each). The reactions were set up in 96-well microtiter plates in triplicate in the presence or absence of the inhibitors. Each well consisted of $2 \mu \mathrm{L}$ of $2 \mathrm{mM} \mathrm{A} \beta 42,2 \mu \mathrm{L}$ of $2 \mathrm{mM}$ inhibitor or solvent, $20 \mu \mathrm{L} 10 \times \mathrm{P}_{50} \mathrm{BS}$ and $176 \mu \mathrm{L} \mathrm{H}_{2} \mathrm{O}$ to final concentration of $200 \mu \mathrm{L}$ per well. The plates were incubated at $37^{\circ} \mathrm{C}$ and samples were taken at 0,16 , and $24 \mathrm{~h}$ after incubation for analysis. Control wells for all solvents and the inhibitor alone were also included in the experiment to exclude any background fluorescents or aggregation related to the color of inhibitor or solvents. $\mathrm{A} \beta_{42}(20 \mu \mathrm{M})$ was diluted with ThT at a ratio of $1: 19$ by volume. The fluorescence was measured using FLUOstar OPTIMA ${ }^{\mathrm{TM}}$ multi-detection microplate reader (BMG Labtechnologies, Melbourne, VIC, Australia) with 440/480-nm excitation/ emission filters set.

\subsection{Sample Preparation of Compounds Co-Incubated with A $\beta_{42}$ Peptide for Gel Electrophoresis}

$\mathrm{A} \beta_{42}$ peptide $(20 \mu \mathrm{M})$ samples were co-incubated with the compounds (potential inhibitors) for 7 day and analyzed by gel electrophoresis. Freshly prepared $A \beta_{42}$ was also included to indicate the effect of inhibitors and incubation time on fibril formation. All of the samples were diluted into sample buffer and boiled for $3 \mathrm{~min}$ and electrophoretically resolved on $4 \%-12 \%$ Bis-Tris pre-cast polyacrylamide gels (NuPAGE ${ }^{\circledR}$ Novex $^{\circledR}$ LDS, Invitrogen ${ }^{\mathrm{TM}}$, Mulgrave, VIC, Australia) in MES running buffer (Cat NP0002, Invitrogen ${ }^{\mathrm{TM}}$ ) at $150 \mathrm{~V}$ for $1 \mathrm{~h}$. Pre stained protein marker (SeeBlue ${ }^{\mathbb{R}}$ Plus2, Cat LC5925, Invitrogen ${ }^{\mathrm{TM}}$ ) were run in parallel for MW comparison. 


\subsection{SDS PAGE and Silver Staining for Detection of $A \beta_{42}$ Oligomers in the Presence of Compounds}

For protein detection, a gel was stained using previously described silver staining methods [73,74]. Briefly, a gel was incubated for $30 \mathrm{~min}$ in $50 \mathrm{~mL}$ of $40 \%$ ethanol (v/v) and $10 \%$ acetic acid (w/v) and subsequently the solution was discarded and the process repeated three times. Then the gel was washed for $10 \mathrm{~min}$ in $\mathrm{dH}_{2} \mathrm{O}$. In order to sensitize, the gel was soaked for $1 \mathrm{~min}$ in $0.02 \% \mathrm{Na}_{2} \mathrm{~S}_{2} \mathrm{O}_{5} \cdot 5 \mathrm{H}_{2} \mathrm{O}$ and then rinsed twice with water $(1 \mathrm{~min})$. The gel was subsequently impregnated with silver for $20 \mathrm{~min}$ using silver solution $\left(0.2 \%\right.$ of $\mathrm{AgNO}_{3}$ and $\left.0.075 \% \mathrm{HCHO}\right)$. After three rinses of $20 \mathrm{~s}$ in water the image was developed in developing solution $\left(0.5 \% \mathrm{HCHO}, 0.0004 \% \mathrm{Na}_{2} \mathrm{~S}_{2} \mathrm{O}_{5} \cdot 5 \mathrm{H}_{2} \mathrm{O}, 6 \% \mathrm{Na}_{2} \mathrm{CO}_{3}\right.$ ) for $10 \mathrm{~min}$. Image development was stopped by adding $40 \%$ ethanol and $10 \%$ acetic acid to the gel and incubating for $10 \mathrm{~min}$. Images from these gels were obtained using the VersaDoc ${ }^{\mathrm{TM}}$ imaging system (Bio-Rad Inc., Hercules, CA, USA).

\subsection{Western-Blot for Detection of Potential A $\beta_{42}$ Fibril Inhibitors}

Aliquots of $A \beta_{42}$ conformers $(25 \mu \mathrm{M})$ were taken from samples of the in situ TEM assays after the incubation period. Fresh $A \beta_{42}$ samples was also prepared and loaded along with $5 \mu \mathrm{L}$ of Novex ${ }^{\circledR}$ Sharp unstained protein standard (Invitrogen ${ }^{\mathrm{TM}}$ ). The proteins $(0.5 \mu \mathrm{g})$ were transferred from the polyacrylamide gel to a nitrocellulose membranes using an iBlot $^{\circledR}$ dry system (Mulgrave, VIC, Australia). The membrane was then blocked for $1 \mathrm{~h}$ in 5\% non-fat dry skim milk in PBS solution and washed three times with PBS. Primary antibody WO2 [75] (University of Melbourne, VIC, Australia), attached to the N-terminal of $A \beta$, was used for detection. This antibody was diluted in PBS/Casein solution (1/200; $0.5 \%$ skim milk in PBS) prior to use. Incubation of the blot in primary antibody for $2 \mathrm{~h}$ continued and was followed by three washes with PBS. Secondary antibody (anti-mouse) was diluted to 1/1000 and incubated on the membrane for $1 \mathrm{~h}$. After washing with PBS, the blot membrane was exposed to ECL chemiluminescent western blotting substrate (ThermoFisher Scientific) for $2 \mathrm{~min}$ and allowed to develop. Images were captured using the VersaDoc ${ }^{\mathrm{TM}}$ imaging system (Bio-Rad Inc.). The immunoreactive bands were later quantified using Quantity One 1-D analysis software (Bio Rad, Australia; version 4.6.8).

\subsection{Transmission Electron Microscope (TEM) Imaging}

Carbon-coated 300-mesh copper grids were glow discharged in nitrogen to render the carbon film hydrophilic. Samples were gently agitated before transferring a $4 \mu \mathrm{L}$ aliquot onto the grids. After $30 \mathrm{~s}$ adsorption time, the excess sample was drawn off using a Whatman ${ }^{\circledR} 541$ filter paper. The grids were then subsequently stained with $2 \% \mathrm{w} / \mathrm{v}$ potassium phosphotungstate $(\mathrm{pH} 7.2)$ for $10 \mathrm{~s}$. The grids were then air dried before examination. The samples were examined using a Tecnai ${ }^{\mathrm{TM}} 12$ Transmission Electron Microscope (FEI, Eindhoven, Netherlands) at an operating voltage of $120 \mathrm{KV}$. Images were recorded using a Megaview III CCD camera and AnalySIS camera control software (Olympus Australia, Macquarie Park, NSW, Australia).

\section{Sample Preparation for TEM}

Freshly prepared aliquots of $A \beta_{42}$ peptide were used for the treatment of the chemicals. The samples were set up in screw cap Eppendorf tubes containing $20 \mu \mathrm{M} \mathrm{A} \beta 42$ peptide, $20 \mu \mathrm{M}$ of the inhibitors, 
and $20 \mu \mathrm{L}$ of a $10 \times$ phosphate buffer stock that gave a final concentration of $50 \mathrm{mM} \mathrm{KH}_{2} \mathrm{PO}_{4} / 300 \mathrm{mM}$ $\mathrm{NaCl} \mathrm{pH} 7.5$ The samples were made up to the final volume of $200 \mu \mathrm{L}$ by adding $\mathrm{H}_{2} \mathrm{O}$. The control sample contained equal amounts of peptide and inhibitor solvents. All of the samples were incubated at $37^{\circ} \mathrm{C}$ for 6 day for TEM analysis.

\subsection{Statistical Analysis}

All samples were analyzed in triplicate and experiments were repeated to ensure their reproducibility. Graphs were made using Microsoft Office Excel 2010 software and data were analyzed using PRISM 5 version 5.04 (GraphPad Software, Inc., La Jolla, CA, USA). All data have been presented as mean \pm SEM. Significant differences were compared using unpaired Student's $t$-test and one-way ANOVA with either Bonferroni's or Tukey's post hoc analysis. Significant differences are indicated by asterisks $\left(^{*}\right)$ and the corresponding $p$-values for the data are given in the text. A $p$-value of $<0.05$ was deemed significant.

\section{Conclusions}

The inhibition of $A \beta_{42}$ aggregation or disaggregation of the preformed oligomers by phenolic compounds that form part of the natural diet show promising evidence that these compounds have anti-amyloidogenic and $\mathrm{AD}$ properties [34,76-78]. Herewith, using a yeast model of AD, we have identified the phenolic compounds that reduced ThT-associated fluorescence and were also capable of reducing the green fluorescence associated with the GFP-A $\beta 42$. These compounds also provided protection against toxicity induced by the HFIP-pretreated $A \beta 42$ peptide. It is known that the protective effect of many phenolic compounds on the aggregation and neurotoxicity effect of $A \beta 42$ peptide is not their only affect $[79,80]$ but they are also able to reduce the inflammation and oxidative stress exacerbated by the accumulation of $\mathrm{A} \beta 42$ peptide. For example, caffeic acids, if present in appreciable concentrations, are known to possess high antioxidant activity due to the presence of 3,4-dihydroxyphenyl moieties and electron-donating groups [81].

All of the known polyphenols that are inhibitors of $A \beta 42$ aggregation are composed of at least two phenolic rings with a minimum of two hydroxyl groups on the aromatic rings, that enables them to strongly interact with peptide residues in $\beta$-sheet regions of oligomers [82]. Our results support the view that certain DHBs destabilize and dissociate amyloid oligomer structure reversibly into monomeric amyloids [46]. For example, the relative placement of hydroxyl groups has a profound effect on chemical activity/redox activity and other interactions. The phenolic hydroxyl groups are capable of neutralizing free radicals, forming aryloxy radicals in the process [83]. Chemically, vicinal hydroxyl groups on aromatic rings can be oxidized to ortho quinones thereby exerting antioxidant effects [84] unlike the 1,3 dihydroxy isomer that can only exert electrophilic activity [85]. The results here revealed that the positions of the hydroxyl moieties on the aromatic rings are the major determinant of their potency and anti-aggregation rather than the number of hydroxyl groups as illustrated by the data for 2,5-DHBA shown in Figures 1 and 5

The benzofuran moiety has also been reported as a potential inhibitor of $A \beta_{42}$ fibril formation $[39,40,86]$. The inhibitory activity is reportedly due to its ability to bind to $A \beta 42$ [86]. This suggests that specific recognition sites for any potential inhibitors on the $A \beta_{42}$ peptide, such as 
the amyloid $\mathrm{C}-10$ to $\mathrm{C}-21$ hydrophobic region, bind and interfere with the aggregation and fibril formation capacity of the peptide. Our ThT analyses for the benzo[b]furan scaffold compounds indicated that their inhibitory effect is temporary. Therefore, further investigation into their underlying mechanism of interactions with the $A \beta_{42}$ peptide is required to elucidate their potential application. Although selected molecules show promising results in the prevention or perhaps the treatment of cognitive deficits, as well as the inhibition of the development of $\mathrm{AD}$, their bioavailability and toxicology in human subjects requires further investigation prior to their clinical application.

\section{Acknowledgments}

This work is supported in part by a grant from the Medical Advances without Animals Trust (MAWA). We thank Lynne Waddington, Manager, Parkville Electron Microscopy Facility, CSIRO Manufacturing Flagship, Parkville, Victoria for support of the TEM studies.

\section{Author Contributions}

Helmut M. Hügel, Danilla Grando and Ian Macreadie conceived and designed the experiments; Afsaneh Porzoor and Joanne Caine performed the experiments; Helmut M. Hügel, Afsaneh Porzoor and Ian Macreadie analyzed the data; Benjamin Alford synthesized compounds. Helmut M. Hügel, Afsaneh Porzoor and Ian Macreadie wrote the paper.

\section{Conflict of Interest}

The authors declare no conflict of interest.

\section{References}

1. Glabe, C.G. Structural classification of toxic amyloid oligomers. J. Biol. Chem. 2008, 283, 29639-29643.

2. Klyubin, I.; Cullen, W.K.; Hu, N.W.; Rowan, M.J. Alzheimer's disease A $\beta$ assemblies mediating rapid disruption of synaptic plasticity and memory. Mol. Brain 2012, doi:10.1186/1756-6606-5-25.

3. Jin, M.; Shepardson, N.; Yang, T.; Chen, G.; Walsh, D.; Selkoe, D.J. Soluble amyloid beta-protein dimers isolated from Alzheimer cortex directly induce Tau hyperphosphorylation and neuritic degeneration. Proc. Natl. Acad. Sci. USA 2011, 108, 5819-5824.

4. Lacor, P.N.; Buniel, M.C.; Chang, L.; Fernandez, S.J.; Gong, Y.; Viola, K.L.; Lambert, M.P.; Velasco, P.T.; Bigio, E.H.; Finch, C.E.; et al. Synaptic targeting by Alzheimer's-related amyloid beta oligomers. J. Neurosci. 2004, 24, 10191-10200.

5. Lambert, M.P.; Barlow, A.K.; Chromy, B.A.; Edwards, C.; Freed, R.; Liosatos, M.; Morgan, T.E.; Rozovsky, I.; Trommer, B.; Viola, K.L.; et al. Diffusible, nonfibrillar ligands derived from A $\beta$ 1-42 are potent central nervous system neurotoxins. Proc. Natl. Acad. Sci. USA 1998, 95, 6448-6453.

6. Wu, H.Y.; Hudry, E.; Hashimoto, T.; Kuchibhotla, K.; Rozkalne, A.; Fan, Z.; Spires-Jones, T.; Xie, H.; Arbel-Ornath, M.; Grosskreutz, C.L.; et al. Amyloid $\beta$ induces the morphological neurodegenerative triad of spine loss, dendritic simplification, and neuritic dystrophies through calcineurin activation. J. Neurosci. 2010, 30, 2636-2649. 
7. Matharu, B.; El-Agnaf, O.; Razvi, A.; Austen, B.M. Development of retro-inverso peptides as anti-aggregation drugs for $\beta$-amyloid in Alzheimer's disease. Peptides 2010, 31, 1866-1872.

8. Härd, T.; Lendel, C. Inhibition of amyloid formation. J. Mol. Biol. 2012, 421, 441-465.

9. Keshet, B.; Good, T. A $\beta$ toxicity inhibitors as probes of A $\beta$ "active-site". Alzheimers Dement. 2010, doi:10.1016/j.jalz.2010.05.806.

10. Cheng, B.; Gong, H.; Xiao, H.; Petersen, R.B.; Zheng, L.; Huang, K. Inhibiting toxic aggregation of amyloidogenic proteins: A therapeutic strategy for protein misfolding diseases. Biochim. Biophys. Acta 2013, 1830, 4860-4871.

11. Harvey, B.S.; Musgrave, I.F.; Ohlsson, K.S.; Fransson, Å.; Smid, S.D. The green tea polyphenol (-)-epigallocatechin-3-gallate inhibits amyloid- $\beta$ evoked fibril formation and neuronal cell death in vitro. Food Chem. 2011, 129, 1729-1736.

12. Ono, K.; Yoshiike, Y.; Takashima, A.; Hasegawa, K.; Naiki, H.; Yamada, M. Potent anti-amyloidogenic and fibril-destabilizing effects of polyphenols in vitro: Implications for the prevention and therapeutics of Alzheimer's disease. J. Neurochem. 2003, 87, 172-181.

13. Pallauf, K.; Rimbach, G. Autophagy, polyphenols and healthy ageing. Ageing Res. Rev. 2013, 12, $237-252$.

14. Qin, R.A.; Yao, X.X.; Huang, Z.Y. Effects of compound danshen tablets on spatial cognition and expression of brain beta-amyloid precursor protein in a rat model of Alzheimer's disease. J. Tradit. Chin. Med. 2012, 32, 63-66.

15. Mandel, S.; Amit, T.; Reznichenko, L.; Weinreb, O.; Youdim, M.B. Green tea catechins as brain-permeable, natural iron chelators-antioxidants for the treatment of neurodegenerative disorders. Mol. Nutr. Food Res. 2006, 50, 229-234.

16. Maurya, P.K.; Rizvi, S.I. Protective role of tea catechins on erythrocytes subjected to oxidative stress during human aging. Nat. Prod. Res. 2009, 23, 1072-1079.

17. Nichols, J.A.; Katiyar, S.K. Skin photoprotection by natural polyphenols: Anti-inflammatory, antioxidant and DNA repair mechanisms. Arch. Dermatol. Res. 2010, 302, 71-83.

18. Qin, X.-Y.; Cheng, Y.; Yu, L.-C. Potential protection of green tea polyphenols against intracellular amyloid $\beta$-induced toxicity on primary cultured prefrontal cortical neurons of rats. Neurosci. Lett. 2012, 513, 170-173.

19. Rezai-Zadeh, K.; Shytle, D.; Sun, N.; Mori, T.; Hou, H.; Jeanniton, D.; Ehrhart, J.; Townsend, K.; Zeng, J.; Morgan, D.; et al. Green tea epigallocatechin-3-gallate (EGCG) modulates amyloid precursor protein cleavage and reduces cerebral amyloidosis in Alzheimer transgenic mice. J. Neurosci. 2005, 25, 8807-8814.

20. Lee, J.W.; Lee, Y.K.; Ban, J.O.; Ha, T.Y.; Yun, Y.P.; Han, S.B.; Oh, K.W.; Hong, J.T. Green tea (-)-epigallocatechin-3-gallate inhibits $\beta$-amyloid-induced cognitive dysfunction through modification of secretase activity via inhibition of ERK and NF- $\mathrm{B}$ pathways in mice. J. Nutr. 2009, 139, 1987-1993.

21. Cox, C.J.; Choudhry, F.; Peacey, E.; Perkinton, M.S.; Richardson, J.C.; Howlett, D.R.; Lichtenthaler, S.F.; Francis, P.T.; Williams, R.J. Dietary (-)-epicatechin as a potent inhibitor of $\beta \gamma$-secretase amyloid precursor protein processing. Neurobiol. Aging 2015, 36, 178-187.

22. Palhano, F.L.; Lee, J.; Grimster, N.P.; Kelly, J.W. Toward the molecular mechanism(s) by which EGCG treatment remodels mature amyloid fibrils. J. Am. Chem. Soc. 2013, 135, 7503-7510. 
23. Wu, A.; Ying, Z.; Gomez-Pinilla, F. Dietary curcumin counteracts the outcome of traumatic brain injury on oxidative stress, synaptic plasticity, and cognition. Exp. Neurol. 2006, 197, 309-317.

24. Lüthi, U.; Schaerer-Brodbeck, C.; Tanner, S.; Middendorp, O.; Edler, K.; Barberis, A. Human $\beta$-secretase activity in yeast detected by a novel cellular growth selection system. Biochim. Biophys. Acta 2003, 1620, 167-178.

25. Edbauer, D.; Winkler, E.; Regula, J.T.; Pesold, B.; Steiner, H.; Haass, C. Reconstitution of $\gamma$-secretase activity. Nat. Cell Biol. 2003, 5, 486-488.

26. Eskelinen, E.-L.; Saftig, P. Autophagy: A lysosomal degradation pathway with a central role in health and disease. Biochim. Biophys. Acta 2009, 1793, 664-673.

27. Pérez-Areales, F.J.; di Pietro, O.; Espargaró, A.; Vallverdú-Queralt, A.; Galdeano, C.; Ragusa, I.M.; Viayna, E.; Guillou, C.; Clos, M.V.; Pérez, B.; et al. Shogaol-huprine hybrids: Dual antioxidant and anticholinesterase agents with $\beta$-amyloid and tau anti-aggregating properties. Bioorg. Med. Chem. Lett. 2014, 22, 5298-5307.

28. Hügel, H.M.; Jackson, N. Danshen diversity defeating dementia. Bioorg. Med. Chem. Lett. 2014, 24, 708-716.

29. Teixeira, J.; Gaspar, A.; Garrido, E.M.; Garrido, J.; Borges, F. Hydroxycinnamic acid antioxidants: An electrochemical overview. Biomed. Res. Int. 2013, doi:10.1155/2013/251754.

30. Wang, X.; Morris-Natschke, S.L.; Lee, K.-H. New developments in the chemistry and biology of the bioactive constituents of Tanshen. Med. Res. Rev. 2007, 27, 133-148.

31. Feng, Y.; You, Z.; Yan, S.; He, G.; Chen, Y.; Gou, X.; Peng, C. Antidepressant-like effects of salvianolic acid B in the mouse forced swim and tail suspension tests. Life Sci. 2012, 90, 1010-1014.

32. Kim, D.H.; Park, S.J.; Kim, J.M.; Jeon, S.J.; Kim, D.H.; Cho, Y.W.; Son, K.H.; Lee, H.J.; Moon, J.H.; Cheong, J.H.; et al. Cognitive dysfunctions induced by a cholinergic blockade and $\mathrm{A} \beta_{25-35}$ peptide are attenuated by salvianolic acid B. Neuropharmacology 2011, 61, 1432-1440.

33. Lee, Y.W.; Kim, D.H.; Jeon, S.J.; Park, S.J.; Kim, J.M.; Jung, J.M.; Lee, H.E.; Bae, S.G.; Oh, H.K.; Son, K.H.; et al. Neuroprotective effects of salvianolic acid B on an A $\beta_{25-35}$ peptide-induced mouse model of Alzheimer's disease. Eur. J. Pharmacol. 2013, 704, 70-77.

34. Shi, L.-L.; Yang, W.-N.; Chen, X.-L.; Zhang, J.-S.; Yang, P.-B.; Hu, X.-D.; Han, H.; Qian, Y.-H.; Liu, Y. The protective effects of tanshinone IIA on neurotoxicity induced by $\beta$-amyloid protein through calpain and the $\mathrm{p} 35 / \mathrm{Cdk} 5$ pathway in primary cortical neurons. Neurochem. Int. 2012, 61, 227-235.

35. Tian, L.L.; Wang, X.J.; Sun, Y.N.; Li, C.R.; Xing, Y.L.; Zhao, H.B.; Duan, M.; Zhou, Z.; Wang, S.Q. Salvianolic acid B, an antioxidant from salvia miltiorrhiza, prevents 6-hydroxydopamine induced apoptosis in SH-SY5Y cells. Int. J. Biochem. Cell Biol. 2008, 40, 409-422.

36. Yu, H.; Yao, L.; Zhou, H.; Qu, S.; Zeng, X.; Zhou, D.; Zhou, Y.; Li, X.; Liu, Z. Neuroprotection against $\mathrm{A} \beta_{25-35}$-induced apoptosis by salvia miltiorrhiza extract in SH-SY5Y cells. Neurochem. Int. 2014, 75, 89-95.

37. Zhou, Y.; Li, W.; Xu, L.; Chen, L. In salvia miltiorrhiza, phenolic acids possess protective properties against amyloid $\beta$-induced cytotoxicity, and tanshinones act as acetylcholinesterase inhibitors. Environ. Toxicol. Pharmacol. 2011, 31, 443-452. 
38. Hudson, S.A.; Ecroyd, H.; Kee, T.W.; Carver, J.A. The thioflavin T fluorescence assay for amyloid fibril detection can be biased by the presence of exogenous compounds. FEBS J. 2009, 276, 5960-5972.

39. Rizzo, S.; Rivière, C.; Piazzi, L.; Bisi, A.; Gobbi, S.; Bartolini, M.; Andrisano, V.; Morroni, F.; Tarozzi, A.; Monti, J.-P.; et al. Benzofuran-based hybrid compounds for the inhibition of cholinesterase activity, $\beta$ amyloid aggregation, and A $\beta$ neurotoxicity. J. Med. Chem. 2008, 51, 2883-2886.

40. Choi, H.-D.; Seo, P.-J.; Son, B.-W.; Kang, B.-W. Synthesis of 5-chloro-3-[4-(3diethylaminopropoxy)benzoyl]-2-(4-methoxyphenyl)benzofuran as a $\beta$-amyloid aggregation inhibitor. Arch. Pharm. Res. 2003, 26, 985-989.

41. Bramanti, E.; Fulgentini, L.; Bizzarri, R.; Lenci, F.; Sgarbossa, A. $\beta$-amyloid amorphous aggregates induced by the small natural molecule ferulic acid. J. Phys. Chem. B 2013, 117, 13816-13821.

42. Levy-Sakin, M.; Shreberk, M.; Daniel, Y.; Gazit, E. Targeting insulin amyloid assembly by small aromatic molecules: Toward rational design of aggregation inhibitors. Islets 2009, 1, 210-215.

43. Gazit, E. A possible role for PI-stacking in the self-assembly of amyloid fibrils. FASEB J. 2002, 16, 77-83.

44. Tartaglia, G.G.; Cavalli, A.; Pellarin, R.; Caflisch, A. The role of aromaticity, exposed surface, and dipole moment in determining protein aggregation rates. Protein Sci. 2004, 13, 1939-1941.

45. Ono, K.; Hamaguchi, T.; Naiki, H.; Yamada, M. Anti-amyloidogenic effects of antioxidants: Implications for the prevention and therapeutics of Alzheimer's disease. Biochim. Biophys. Acta 2006, 1762, 575-586.

46. Jayamani, J.; Shanmugam, G. Gallic acid, one of the components in many plant tissues, is a potential inhibitor for insulin amyloid fibril formation. Eur. J. Med. Chem. 2014, 85, 352-358.

47. LeVine, H., 3rd; Lampe, L.; Abdelmoti, L.; Augelli-Szafran, C.E. Dihydroxybenzoic acid isomers differentially dissociate soluble biotinyl-A $\beta(1-42)$ oligomers. Biochemistry 2012, 51, 307-315.

48. Hawkes, C.A.; Deng, L.-H.; Shaw, J.E.; Nitz, M.; McLaurin, J. Small molecule $\beta$-amyloid inhibitors that stabilize protofibrillar structures in vitro improve cognition and pathology in a mouse model of alzheimer's disease. Eur. J. Neurosci. 2010, 31, 203-213.

49. Ehrnhoefer, D.E.; Bieschke, J.; Boeddrich, A.; Herbst, M.; Masino, L.; Lurz, R.; Engemann, S.; Pastore, A.; Wanker, E.E. EGCG redirects amyloidogenic polypeptides into unstructured, off-pathway oligomers. Nat. Struct. Mol. Biol. 2008, 15, 558-566.

50. Kim, W.; Kim, Y.; Min, J.; Kim, D.J.; Chang, Y.T.; Hecht, M.H. A high-throughput screen for compounds that inhibit aggregation of the Alzheimer's peptide. ACS Chem. Biol. 2006, 1, 461-469.

51. Caine, J.; Sankovich, S.; Antony, H.; Waddington, L.; Macreadie, P.; Varghese, J.; Macreadie, I. Alzheimer's A $\beta$ fused to green fluorescent protein induces growth stress and a heat shock response. FEMS Yeast Res. 2007, 7, 1230-1236.

52. Wurth, C.; Guimard, N.K.; Hecht, M.H. Mutations that reduce aggregation of the Alzheimer's A $\beta_{42}$ peptide: An unbiased search for the sequence determinants of A $\beta$ amyloidogenesis. J. Mol. Biol. 2002, 319, 1279-1290. 
53. Iwai, K.; Naganuma, A.; Kuge, S. Peroxiredoxin Ahpl acts as a receptor for alkylhydroperoxides to induce disulfide bond formation in the Cad1 transcription factor. J. Biol. Chem. 2010, 285, 10597-10604.

54. Lian, F.M.; Yu, J.; Ma, X.X.; Yu, X.J.; Chen, Y.; Zhou, C.Z. Structural snapshots of yeast alkyl hydroperoxide reductase $A h p 1$ peroxiredoxin reveal a novel two-cysteine mechanism of electron transfer to eliminate reactive oxygen species. J. Biol. Chem. 2012, 287, 17077-17087.

55. Bharadwaj, P.R.; Verdile, G.; Barr, R.K.; Gupta, V.; Steele, J.W.; Lachenmayer, M.L.; Yue, Z.; Ehrlich, M.E.; Petsko, G.; Ju, S.; et al. Latrepirdine (dimebon) enhances autophagy and reduces intracellular GFP-A $\beta_{42}$ levels in yeast. J. Alzheimers Dis. 2012, 32, 949-967.

56. Porzoor, A.; Caine, J.M.; Macreadie, I.G. Pretreatment of chemically-synthesized A $\beta_{42}$ affects its biological activity in yeast. Prion 2014, 8, 404-410.

57. Walsh, D.M.; Townsend, M.; Podlisny, M.B.; Shankar, G.M.; Fadeeva, J.V.; el Agnaf, O.; Hartley, D.M.; Selkoe, D.J. Certain inhibitors of synthetic amyloid $\beta$-peptide (A $\beta)$ fibrillogenesis block oligomerization of natural $\mathrm{A} \beta$ and thereby rescue long-term potentiation. J. Neurosci. 2005, $25,2455-2462$.

58. Wang, Q.; Walsh, D.M.; Rowan, M.J.; Selkoe, D.J.; Anwy, L.R. Block of long-term potentiation by naturally secreted and synthetic amyloid $\beta$-peptide in hippocampal slices is mediated via activation of the kinases c-Jun N-terminal kinase, cyclin-dependent kinase 5, and p38 mitogen-activated protein kinase as well as metabotropic glutamate receptor type 5. J. Neurosci. 2004, 24, 3370-3378.

59. Blanchard, B.J.; Chen, A.; Rozeboom, L.M.; Stafford, K.A.; Weigele, P.; Ingram, V.M. Efficient reversal of Alzheimer's disease fibril formation and elimination of neurotoxicity by a small molecule. Proc. Natl. Acad. Sci. USA 2004, 101, 14326-14332.

60. De Felice, F.G.; Vieira, M.N.; Saraiva, L.M.; Figueroa-Villar, J.D.; Garcia-Abreu, J.; Liu, R.; Chang, L.; Klein, W.L.; Ferreira, S.T. Targeting the neurotoxic species in Alzheimer's disease: Inhibitors of A $\beta$ oligomerization. FASEB J. 2004, 18, 1366-1372.

61. Esler, W.P.; Stimson, E.R.; Ghilardi, J.R.; Felix, A.M.; Lu, Y.A.; Vinters, H.V.; Mantyh, P.W.; Maggio, J.E. A $\beta$ deposition inhibitor screen using synthetic amyloid. Nat. Biotechnol. 1997, 15, $258-263$.

62. Nakagami, Y.; Nishimura, S.; Murasugi, T.; Kaneko, I.; Meguro, M.; Marumoto, S.; Kogen, H.; Koyama, K.; Oda, T. A novel $\beta$-sheet breaker, RS-0406, reverses amyloid $\beta$-induced cytotoxicity and impairment of long-term potentiation in vitro. Br. J. Parmacol. 2002, 137, 676-682.

63. Vitalis, A.; Caflisch, A. Micelle-like architecture of the monomer ensemble of Alzheimer's amyloid- $\beta$ peptide in aqueous solution and its implications for A $\beta$ aggregation. J. Mol. Biol. 2010, 403, 148-165.

64. Giuffrida, M.L.; Caraci, F.; de Bona, P.; Pappalardo, G.; Nicoletti, F.; Rizzarelli, E.; Copani, A. The monomer state of $\beta$-amyloid: Where the Alzheimer's disease protein meets physiology. Rev. Neurosci. 2010, 21, 83-93.

65. Morris, A.M.; Watzky, M.A.; Finke, R.G. Protein aggregation kinetics, mechanism, and curve-fitting: A review of the literature. Biochim. Biophys. Acta 2009, 1794, 375-397.

66. Teplow, D.B. Structural and kinetic features of amyloid $\beta$-protein fibrillogenesis. Amyloid 1998, $5,121-142$. 
67. Walsh, D.M.; Selkoe, D.J. A $\beta$ oligomers-A decade of discovery. J. Neurochem. 2007, 101, 1172-1184.

68. Alford, B.L.; Hügel, H.M. Total synthesis of (+)-pentamethylsalvianolic acid C. Org. Biomol. Chem. 2013, 11, 2724-2727.

69. Ryan, T.M.; Caine, J.; Mertens, H.D.; Kirby, N.; Nigro, J.; Breheney, K.; Waddington, L.J.; Streltsov, V.A.; Curtain, C.; Masters, C.L.; et al. Ammonium hydroxide treatment of A $\beta$ produces an aggregate free solution suitable for biophysical and cell culture characterization. PeerJ 2013, doi:10.7717/peerj.73.

70. Ryan, T.M.; Friedhuber, A.; Lind, M.; Howlett, G.J.; Masters, C.; Roberts, B.R. Small amphipathic molecules modulate secondary structure and amyloid fibril-forming kinetics of Alzheimer disease peptide A (1-42). J. Biol. Chem. 2012, 287, 16947-16954.

71. De Ferrari, G.V.; Mallender, W.D.; Inestrosa, N.C.; Rosenberry, T.L. Thioflavin T is a fluorescent probe of the acetylcholinesterase peripheral site that reveals conformational interactions between the peripheral and acylation sites. J. Biol. Chem. 2001, 276, 23282-23287.

72. Maezawa, I.; Hong, H.-S.; Liu, R.; Wu, C.-Y.; Cheng, R.H.; Kung, M.-P.; Kung, H.F.; Lam, K.S.; Oddo, S.; LaFerla, F.M.; et al. Congo red and thioflavin-T analogs detect A $\beta$ oligomers. J. Neurochem. 2008, 104, 457-468.

73. Blum, H.; Beier, H.; Gross, H.J. Improved silver staining of plant proteins, RNA and DNA in polyacrylamide gels. Electrophoresis 1987, 8, 93-99.

74. Rabilloud, T.; Vuillard, L.; Gilly, C.; Lawrence, J.J. Silver-staining of proteins in polyacrylamide gels: A general overview. Cell. Mol. Biol. 2009, 40, 57-75.

75. Miles, L.A.; Wun, K.S.; Crespi, G.A.; Fodero-Tavoletti, M.T.; Galatis, D.; Bagley, C.J.; Beyreuther, K.; Masters, C.L.; Cappai, R.; McKinstry, W.J.; et al. Amyloid- $\beta$-anti-amyloid- $\beta$ complex structure reveals an extended conformation in the immunodominant B-cell epitope. J. Mol. Biol. 2008, 377, 181-192.

76. Zhang, J.; Mori, A.; Chen, Q.; Zhao, B. Fermented papaya preparation attenuates $\beta$-amyloid precursor protein: $\beta$-Amyloid-mediated copper neurotoxicity in $\beta$-amyloid precursor protein and $\beta$-amyloid precursor protein swedish mutation overexpressing SH-SY5Y cells. Neuroscience 2006, 143, 63-72.

77. Williams, P.; Sorribas, A.; Howes, M.J. Natural products as a source of Alzheimer's drug leads. Nat. Prod. Rep. 2011, 28, 48-77.

78. Ji, H.F.; Zhang, H.Y. Multipotent natural agents to combat Alzheimer's disease. Functional spectrum and structural features. Acta Pharmacol. Sin. 2008, 29, 143-151.

79. Sul, D.; Kim, H.S.; Lee, D.; Joo, S.S.; Hwang, K.W.; Park, S.Y. Protective effect of caffeic acid against beta-amyloid-induced neurotoxicity by the inhibition of calcium influx and tau phosphorylation. Life Sci. 2009, 84, 257-262.

80. Wang, S.-X.; Hu, L.-M.; Gao, X.-M.; Guo, H.; Fan, G.-W. Anti-inflammatory activity of salvianolic acid B in microglia contributes to its neuroprotective effect. Neurochem. Res. 2010, 35, 1029-1037.

81. Zhao, G.R.; Zhang, H.M.; Ye, T.X.; Xiang, Z.J.; Yuan, Y.J.; Guo, Z.X.; Zhao, L.B. Characterization of the radical scavenging and antioxidant activities of danshensu and salvianolic acid B. Food Chem. Toxicol. 2008, 46, 73-81. 
82. Porat, Y.; Abramowitz, A.; Gazit, E. Inhibition of amyloid fibril formation by polyphenols: Structural similarity and aromatic interactions as a common inhibition mechanism. Chem. Biol. Drug Des. 2006, 67, 27-37.

83. Mythri, R.B.; Harish, G.; Raghunath, N.; Bharath, M.S. Therapeutic potential of polyphenols in Parkinson's disease. In Towards New Therapies for Parkinson's Disease; Intech: Rijecka, Croatia, 2011; pp. 115-150.

84. Rice-Evans, C.A.; Miller, N.J.; Paganga, G. Structure-antioxidant activity relationships of flavonoids and phenolic acids. Free Radic. Biol. Med. 1996, 20, 933-956.

85. Dickinson, D.A.; Iles, K.E.; Zhang, H.; Blank, V.; Forman, H.J. Curcumin alters EpRE and AP-1 binding complexes and elevates glutamate-cysteine ligase gene expression. FASEB J. 2003, 17, 473-475.

86. Howlett, D.R.; Perry, A.E.; Godfrey, F.; Swatton, J.E.; Jennings, K.H.; Spitzfaden, C.; Wadsworth, H.; Wood, S.J.; Markwell, R.E. Inhibition of fibril formation in $\beta$-amyloid peptide by a novel series of benzofurans. Biochem. J. 1999, 340, 283-289.

Sample Availability: Samples of the phenolic compounds are available from the authors.

(C) 2015 by the authors; licensee MDPI, Basel, Switzerland. This article is an open access article distributed under the terms and conditions of the Creative Commons Attribution license (http://creativecommons.org/licenses/by/4.0/). 